\title{
UM CAPÍTULO DA HISTÓRIA DA FORMAÇÃO E DA PROFISSÃO DOCENTE NO BRASIL: O INSTITUTO DE EDUCAÇÃO DO DISTRITO FEDERAL E SUA HISTORIOGRAFIA*
}

\begin{abstract}
RESUMO: $\mathrm{O}$ artigo trata da historiografia do movimento educacional brasileiro entre 1920 e 30, especialmente acerca da formaçáo docente. Por um lado, discute a relevância do Instituto Superior de Educação do Rio de Janeiro (ISERJ) para entender o período e o tema. Sugere que essa instituição foi marcada por transformaçóes na memória do movimento educacional nos anos 1920 e 30 . Por outro lado, aborda o significado das atuais discussóes sobre a formação de professores para as interpretaçóes a respeito do ISERJ. Por fim, reflete sobre uma mudança fundamental na forma como respondemos ao desafio de formar para a docência. A conclusão afirma a distância entre um programa de enobrecimento excludente, seletivo e elitista do preparo do professor no passado e as atuais práticas de desqualificação ampla e geral do exercício docente.
\end{abstract}

André Luiz Paulilo ${ }^{1}$

Palavras-chave: Historiografia. Instituto de Educação do Rio de Janeiro. Questôes atuais da Formação de Professores. Movimento educacional brasileiro (1920-1930).

\section{A CHAPTER IN THE HISTORY OF EDUCATION AND THE TEACHING PROFESSION IN BRAZIL: EDUCATION INSTITUTE OF THE FEDERAL DISTRICT AND ITS HISTORIOGRAPHY}

\begin{abstract}
This paper focuses the historiography of the Brazilian educational movement between 1920 and 1930, especially about the training for teaching. On one hand, it discusses the relevance of the Education Institute of Rio de Janeiro (ISERJ) to understand the period and the theme. It suggests that this institution was marked by the transformation in the education movement memory. On the other hand, it examines the meaning of the current discusses about the training for teaching to the interpretations on the ISERJ. Finally, the text reflects about a major change in how we respond to the challenge of training
\end{abstract}

\footnotetext{
*Projeto de Pesquisa do qual resultou o artigo: A escola nova em São Paulo e no Rio de Janeiro: propagação e circularidade de modelos pedagógicos no início do século XX no Brasil. Agência de fomento: CNPq. ${ }^{1}$ Departamento de Filosofia e História da Educaçáo da Faculdade de Educação da Universidade Estadual de Campinas (UNICAMP) - Campinas (SP), Brasil. E-mail: paulilo@unicamp.br DOI: $10.1590 / \mathrm{ES} 0101-73302016139962$
} 
for teaching. The conclusion affirms the gap between an ennobling exclusionary, selective and elitist program of teacher preparation in the past and the current practices of disqualification of the teaching exercise.

Keywords: Historiography. Education Institute of Rio de Janeiro. Current issues of training for teaching. Brazilian educational movement (1920-1930).

\section{UN CHAPITRE DE L'HISTOIRE DE L'ÉDUCATION ET DE LA PROFESSION D'ENSEIGNANT AU BRÉSIL : L'INSTITUT D'ÉDUCATION DU DISTRICT FÉDÉRAL ET SON HISTORIOGRAPHIE}

RÉSUMÉ : Cette article traite l'historiographie du mouvement éducatif brésilien entre 1920 et 1935, en particulier les études de la formation des enseignants. D'un côté, on discute l'importance de l'Institut d'Éducation de Rio de Janeiro (ISERJ) pour comprendre la période et le thème. On suggère que cette institution a été marquée par changements dans la mémoire du mouvement éducatif des années 1920 et 1930 . D'autre part, on examine la signification des discussions en cours sur la formation des enseignants pour l'interprétation de l'Institut d'Éducation de Rio de Janeiro. Enfin, on réfléchit sur un changement fondamental dans la façon dont nous répondons au défi de la formation pour l'enseignement. La conclusion indique la distance entre une programme d'ennoblissement, sélectif and élitiste, de préparation des enseignants dans le passé et les pratiques actuelles de disqualification d'activité d'enseignant.

Mots-clés : Historiographie. Institut d'Éducation de Rio de Janeiro. Enjeux actuels de la formation des enseignants. Mouvement éducatif brésilien (1920-1935).

\section{Introdução}

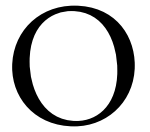

acúmulo de estudos sobre a formação docente nos anos 1920 e 30 beneficia a compreensão de um projeto do grupo dos chamados renovadores da educação. Trata-se de variadas perspectivas de investigação acerca da maneira de conceber o papel da universidade e de sua relação com a formaçáo de professores tendo em vista o movimento da Escola Nova e o pensamento educacional liberal. Essa preocupação reuniu teses e dissertaçóes em torno da análise das instituiçôes de formação docente nos diferentes estados brasileiros. Recentemente, somam-se pesquisas em quantidade no que diz respeito às escolas normais que têm posto em questão os critérios de recrutamento dos professores, os saberes e os habitus requeridos do futuro docente e mesmo os meios de formação para o magistério no Brasil. 
No conjunto desse acumulado de produçóes, destaca-se uma série de monografias concernentes ao Instituto de Educação da então capital federal, o Rio de Janeiro. No período de uma década, entre 1993 e 2003, cinco doutoramentos e uma dissertação falaram do instituto organizado, em 1932, por Anísio Teixeira. $\mathrm{O}$ volume de pesquisa histórica entáo reunido e ainda na atualidade debatido sobre a formação docente na capital do país entre 1928 e 1935 sugere a atualidade do tema. Repensar uma experiência vivida há oito décadas tem significado refletir acerca dos contrastes entre as possibilidades de aperfeiçoamento e desenvolvimento autônomo dos profissionais da educação e a espécie de inércia institucional que ainda hoje impede um encaminhamento adequado das questóes relativas à formação de professores para as escolas de ensino fundamental e médio. Mesmo parcial, o inventário dos estudos que se propuseram a compreender essa experiência propicia condiçóes para explorar os limites do pensamento liberal em relação à problemática da formação especializada do magistério.

A historiografia do Instituto de Educação do Rio de Janeiro que se quis empreender aqui trata do modo como a história da educação vem problematizando questôes referentes às instituições de formação de professores. Assim, segue-se uma reflexão que em primeiro lugar discute os discursos de excelência e de aprimoramento profissional do magistério que foram compilados em teses produzidas entre 1993 e 2003 sobre a transformação da Escola Normal do Distrito Federal em Instituto de Educaçáo. Depois, é explorado o viés de estudo da história da formação docente constituído pelo conjunto de teses preocupadas em levantar as condiçóes nas quais a historiografia manifestou e desenvolveu o seu interesse pelo tema durante o período em que também foi elaborada, regulamentada e implantada a Nova Lei de Diretrizes e Bases da Educação (LDB).

\section{A Universidade da Educação}

Duas questóes surgem com particular clareza da discussão que a tese de doutorado de Mendonça (1993) faz do papel do Instituto de Educação na criação da Universidade do Distrito Federal (UDF). Em primeiro lugar, há a relevância que a Escola de Educação assumiu no interior desse projeto de universidade. Fundamentalmente, Mendonça (2002) argumenta que, na prática, a UDF acabou por se dedicar à formação de professores. É significativo que, assim, tenha apresentado a Escola de Educaçáo do instituto como o cerne da universidade, refletindo sobre a visão de Anísio Teixeira acerca do papel do profissional de educação enquanto intelectual. Mendonça (2002) insiste no fato de Anísio Teixeira ter concebido a formação do professor sobre bases científicas, sendo imprescindível destacar a Escola Normal do curso secundário e redefini-la como um curso de nível universitário. Para Anísio Teixeira, as "bases científicas" do trabalho docente compreendiam mais que a preparação didático-metodológica, "as ciências 
humanas e sociais aplicadas à educação [...] e a filosofia" (TEIXEIRA apud MENDONÇA, 2002, p. 92). Por esse enfoque, o que se propunha com a organização do preparo docente em nível superior era dar aos mestres a atitude científica, isto é, "de experimentação, de ensaio em relação a ideias e teorias, e de respeito em relação aos fatos comprovados" (TEIXEIRA apud MENDONÇA, 2002, p. 93).

Em segundo lugar, tem-se a importância da formação dos especialistas em educação. Como bem advertiu Mendonça (2002, p. 103), Anísio Teixeira diferenciava claramente o professor daqueles a quem chamava de "especialistas de educação". Com base no que se depreende da análise de Mendonça (2002), a incorporaçáo da Escola de Professores à UDF tinha o objetivo de formar esses especialistas, "que se constituiriam em verdadeiros intelectuais da educaçáo, os mestres dos mestres" (MENDONÇA, 2002, p. 104). De fato, a Escola de Educação foi organizada por Anísio Teixeira com vistas a formar e empregar intelectuais capazes de exercer a direção da educação no país. Nessa perspectiva, a Escola de Educação não só devia firmar-se como "centro de pesquisas educacionais" e "foco de irradiação nacional das ciências da educação", mas, igualmente, enquanto "possibilidade de melhoria contínua da qualificação" (TEIXEIRA apud MENDONÇA, 2002, p. 93).

Assim, a discussão que a tese de Mendonça, de 1993, proporciona à especialização da carreira docente não se limita ao modo de conceber o papel social do educador, no entanto também inclui a compreensão do trabalho desenvolvido na Escola de Professores. Sobretudo, ela é significativa aqui para ressaltar que a UDF foi estabelecida para ser um espaço onde o saber fosse construído e transmitido de forma socializada. $\mathrm{Na}$ estrutura geral pensada por Anísio Teixeira para o curso de formação de professores, a especialização em educação seria essencialmente filosófica e política, "mais obra de pensadores e políticos do que propriamente de técnicos" (TEIXEIRA apud MENDONÇA, 2002, p. 106).

Outra perspectiva de análise do programa de formação para o magistério desenvolvido no ISERJ nos anos 1920 e 30 diz respeito aos dispositivos para a introduçáo de uma nova prática docente por parte das administraçóes de Fernando de Azevedo e Anísio Teixeira. A institucionalização do estudo científico da educação abrangeu uma variedade de expedientes, um conjunto de iniciativas que confeririam materialidade às propostas de renovação do preparo inicial dos professores na então capital do país. Vidal $(1995,2001)$ esclarece parte desses expedientes quando trata da prática do inquérito e das políticas relativas ao livro e à leitura como dispositivos de formação docente. Também Accácio (1993, 2001) abordou alguns dos instrumentos utilizados para transformar a Escola de Professores em um campo de experimentação e testes de novos métodos e teorias para o processo educativo. Entre as práticas que enfatizou, estão o aparelhamento do edifício, o concurso para docentes e as manobras curriculares. Principalmente, a indagação acerca das práticas que constituíram a experiência singular do Instituto 
de Educação remete-se a um tempo e a um lugar institucional em que se apostava, conforme bem avaliou Carvalho (2001, p. 13), "na escola e no seu poder de transformação cultural".

As análises de Accácio $(1993,2001)$ sugerem que o aparelhamento do edifício, o concurso para docentes e as manobras curriculares foram açóes organizadas no interior de um projeto político que buscava conciliar mudança social e democracia - tanto a monumentalidade e a equipagem do novo edifício da Escola Normal quanto a superação do autodidatismo e do fisiologismo no exercício da docência, atitudes que a pesquisa de Accácio (1993, p. 77) indica representar "um movimento claro e concreto no sentido da preocupação dos reformadores com a melhoria da formação do professor". Em parte, tratava-se de uma preocupação com a prática de ensino, com o ensino empírico em vez de exclusivamente teórico, com a arquitetura do espaço de formação docente, com a contratação dos professores da Escola Normal e com as orientaçóes do trabalho educativo. Por outro lado, as mudanças no domínio curricular, com acréscimo de disciplinas, desempenharam seu papel na seleçáo de professores, redundando na organizaçáo de provas de capacidade didática por ocasiáo dos concursos para a cátedra da Escola Normal. Enfim, as bases científicas sob as quais Anísio Teixeira concebeu as seçôes da Escola de Educação e em que assentou as práticas e os métodos educativos ali ensinados, segundo Accácio (1993), mantiveram uma atitude de preocupação permanente diante dos problemas de cultura geral. Considerava-se formar o professor em um processo "mais amplo do que apenas lhe dar técnicas" (ACCÁCIO, 1993, p. 257). De vários modos, portanto, as conclusóes da pesquisa de Accácio (1993) mostraram os elementos determinantes das alteraçóes conduzidas por Fernando de Azevedo e Anísio Teixeira, ligados a um conjunto renovado de doutrinas sobre a educação.

Particularmente consistente é a compreensão que Vidal (2001) apresenta acerca do que lhe pareceu singular na experiência do Instituto de Educação entre 1932 e 1937 . Seu estudo sobre as prescriçóes de leitura e os modos de ler e utilizar o que se leu na Escola de Professores nos anos 1930 relaciona o livro e a leitura aos dispositivos para a introdução de uma nova prática docente. Por meio do exame dos registros da biblioteca do Instituto de Educação sobre doaçôes e aquisiçóes, dos títulos dos livros incorporados aos acervos, dos registros de consulta e das bibliografias dos cursos, sugere que a constituição de uma biblioteca para auxiliar a formação de professores aglutinava, de maneira especial, discursos de excelência e de aprimoramento profissional (VIDAL, 2001). Outra singularidade das práticas que constituíram a experiência do Instituto de Educação sob a gestão de Anísio Teixeira tratada pela autora foi a realização de inquéritos na rotina escolar das alunas. A abordagem do modo como o instituto se ocupava com a prática docente tornou evidente que o inquérito servia como um dispositivo de formação. Vidal (2001) percebeu que essa foi uma estratégia para incorporar hábitos e habilidades de observação e de experimentação e fazer as alunas compreender a investigação como um procedimento essencial ao exercício da docência. 
Os resultados das pesquisas feitas por Vidal (2001) e Accácio (1993, 2001) advertem sobre o caráter indissociável da especialização do trabalho docente e as condiçóes da sua produção. A preocupação dos autores com as manobras de reforma do ensino normal e as práticas de formaçáo docente dimensiona o lugar ocupado e o papel desempenhado pela Escola de Professores do Instituto de Educação na ruptura que se promoveu nos saberes e fazeres docentes nos anos 1920 e 30. Como nas reflexóes de Mendonça (2002), ambas as análises incitam o reexame da organização dos atuais cursos de formação de professores, seja porque enriquecem o debate pelo estudo histórico de uma experiência de preparo para a docência ainda incipiente, seja porque remetem a outro modelo de formação para o magistério. De todo modo, os métodos de projetos, os centros de interesse e o self-government, entre outras variadas inovaçóes que haviam sido pensadas e experimentadas no Instituto de Educação, alimentaram em geraçôes de professoras da capital, conforme mostram Schaffel (1999) e Lopes (2006), todo um sistema de representaçóes no que concerne ao exercício da docência.

Os estudos sobre as memórias de professoras formadas no Instituto de Educação permitem pensar os resultados das pesquisas de arquivo sob duas importantes perspectivas. Por um lado, há o ângulo das apropriaçóes pessoais das mudanças do ensino normal promovidas pelas reformas da instrução pública desde a administraçáo de Fernando de Azevedo. Por outro, a representação que essas antigas professoras guardam de si e da profissão também fica visível nos depoimentos. Não só as lembranças de docentes e especialistas da educação egressas do instituto acusam a prática dos métodos ativos de ensino, de acordo com a chamada Escola Nova, como consolidam um ideal de formação, um modelo profissional apreendido e exercido. Sobretudo o doutoramento de Schaffel (1999) explora essas reminiscências segundo métodos que deixam ver como as professoras primárias formadas pelo Instituto de Educação "absorveram e trabalharam os valores e normas da profissão, aprendidos na agência formadora e referendados pelo contexto social" (SCHAFFEL, 1999, p. 222).

Assim, em seu estudo sobre a construçáo da identidade docente no Instituto de Educação, Schaffel (1999) percebeu que o ideal proclamado pelos fundadores da instituição foi lembrado como ideal realizado por suas alunas. Tanto a apropriação de novas metodologias quanto a manifestação de interesses, habilidades e aptidóes em torno de grupos associativos formados na Escola de Educação do instituto aparecem nos depoimentos compilados pela autora. Diante disso, ela avaliou que, de fato, a dinâmica do curso de formação de professores da então capital do país "deu espaço para o surgimento de uma cultura de ofício, mantida por um sistema de normas e valores internamente desenvolvidos, que vinham ao encontro da comunidade" (SCHAFFEL, 1999, p. 226). A continuidade entre o ser aluna mestre do Instituto de Educação e o ser mestra na escola primária da rede pública de ensino é uma presença conspícua nas lembranças das professoras entrevistadas, indicando apropriaçóes de práticas e valores. 
Do ponto de vista das representaçóes de si e da profissão, as ex-normalistas entrevistadas por Schaffel (1999) asseguraram que a construção das suas identidades pessoais e profissionais passou pelo "reconhecimento social da profissão de professor, pelas recompensas materiais e simbólicas de pertencer a um quadro altamente seletivo" (SCHAFFEL, 1999, p. 229). Também tratadas por Nunes (2000) e Vidal (2001), as questóes relativas à estruturação de um campo de identificação dos educadores envolveram um conjunto de valores, hábitos, rotinas, recursos, estratégias, posturas e princípios que não só foram identificadores de geraçóes de professoras, mas identificados como de excelência pela sociedade. Com espaço físico planejado para abrigar diversos ambientes de aprendizagem, assim como atividades sociais, intelectuais, artísticas e esportivas, rigorosos critérios de admissão, estudos de matérias de ensino e cursos extraordinários, de especialização, aperfeiçoamento e extensão, o instituto produziu sentidos duradouros sobre as vivências e as experiências da vida docente na capital do país.

A exploração de pesquisa efetuada por Lopes (2006) fundamentada em questóes a professores e implementadores do atual curso Normal Superior do ISERJ conduz a outro entendimento da memória sobre o instituto. A pergunta com que a autora deparou após questionar 30 desses professores com mais de 20 anos de efetivo exercício no ISERJ foi a respeito dos motivos da ausência, em suas memórias discentes, de qualquer registro consistente quanto à criação do instituto ou de sua Escola de Educação. A questão que se colocou é a do próprio lugar do instituto na memória do movimento de reconstrução educacional do Brasil nos anos 1920 e 30. Lopes (2006) responde a isso ao menos de dois modos. Primeiramente, explica que existiu a intenção de apagar a memória dos "pioneiros" pelo projeto educacional que se estabeleceu após 1939. Depois, argumenta que, apesar da inviabilidade política da Escola de Educação do instituto, algumas das práticas renovadoras da instituição enraizaram-se na experiência docente de suas ex-alunas.

Expressivamente, Lopes (2006) faz referências aos acontecimentos que limitaram a possibilidade de consolidação "de um projeto que não convinha ser lembrado num momento em que a política educacional seguia tendências cada vez mais autoritárias" (LOPES, 2006, p. 309). Identifica a vontade política de apagar a obra educacional experimentada pelo Instituto de Educação entre 1932 e 1935 tanto na legislação quanto nas reformas curriculares do período posterior, no entanto a autora não descuida das manifestaçóes que "no nível do universo simbólico" se traduziram como o retrato de uma geração. Assim, percebe as tradiçóes, os rituais, as festas cívicas e os hinos reunidos nas revistas dos alunos como parte de uma experiência de formação vivamente conservada nas muitas lembranças de um tempo e de um lugar em que preparar professores significava conscientizar uma elite de ofício da sua missão de educar os filhos da classe trabalhadora. 


\section{O desafio de formar para a docência e a História}

Prática comum a toda essa série de pesquisas sobre a história do Instituto de Educação é a da referência ao modelo institucional do preparo para o magistério atualmente. Não que haja um cotejo sistemático, mas a preocupação com as mudanças de compromisso quanto à formaçáo inicial do profissional em educação também resultou em reflexão histórica. Os estudos de Mendonça (2002), Accácio (1993, 2001), Vidal (2001), Schaffel (1999) e Lopes (2006) chamam a atenção para a singularidade do Instituto de Educação sob a gestão partilhada de Anísio Teixeira e Manoel Bergstrom Lourenço Filho. Igualmente, esses autores contribuem para o debate acerca das atuais relaçôes que a universidade mantém com os cursos de formaçáo docente, os dispositivos para a introduçáo de uma nova prática docente e a maneira como o professor se reconhece e é reconhecido pela sociedade.

Mendonça (2002) expressa textualmente que seu estudo se direcionou para o momento histórico no qual os cursos de licenciatura foram instituídos no país por conta da constatação de que a universidade brasileira tem se mostrado incapaz, ao longo do tempo, de resolver o problema da formação de professores para a educação fundamental e média. De acordo com o que escreveu na apresentação dos resultados de pesquisa, "alguns dos principais problemas evidenciados na literatura pedagógica se arrastam desde os primórdios desses cursos" (MENDONÇA, 2002, p. 15). É semelhante o modo como Lopes (2006) apresenta as suas questóes de investigação. Diante da comprovação dos problemas em relação aos cursos de licenciatura e do desprestígio social da carreira docente, a autora pergunta-se sobre ideias e práticas que ajudam a pensar a formação de professores para além do que dispóe a atual legislação em vigor. Sobretudo, Lopes (2006) diz ter encontrado no estudo da história do Instituto de Educação uma forma de construção dos saberes docentes que atualmente "não passa de mera figura de retórica para a grande maioria dos cursos superiores que se dedicam à formação docente" (LOPES, 2006, p. 312).

Como Mendonça (2002) e Lopes (2006), Accácio (1993) também inicia suas pesquisas sobre o Instituto de Educação tendo em vista a experiência vivida no ensino do Rio de Janeiro. A autora assumiu ter buscado no passado a informação para o futuro, em uma clara preocupação com os caminhos seguidos pela educação e com o compromisso associado à valorização da escola. Parte de suas questóes teve como base a concepção e a valorização do profissional que os reformadores desejavam formar no Instituto de Educação à época. Assim, a busca por um momento de valorizaçáo do investimento na formação de professores para a educação básica visava achar pistas de questôes acerca da história de uma categoria profissional atualmente táo desprestigiada no Brasil. Esse âmbito de investigação é ainda o de Schaffel (1999), que ante a análise das interaçôes sociais 
ocorridas em uma instituição escolar de formação do magistério do porte que teve o Instituto de Educação percebeu a perda da sua força identitária como estruturador da profissão docente. Embora tenha havido todo o cuidado para náo realçar o perfil canônico predominante na literatura sobre o mundo dos professores primários, a pesquisa de Schaffel (1999) mostra a corrosão do poder interno à profissão, mediante a degradação salarial e o desprestígio social dos valores coletivos e das experiências ligados à "tradiçấo" do ofício docente. Logo, é todo um processo de construção da identidade profissional de várias gerações de professoras primárias que se vai apagando com o declínio do modelo de formação docente instituído quando da criação do Instituto de Educação, em 1932.

Portanto, há a percepção de um hiato entre a política de formação que Anísio Teixeira e Manoel Bergstrom Lourenço Filho, entre outros, construíram no Instituto de Educação e os problemas com que defrontamos hoje em dia no campo da educação. Se, na compreensão de alguns, a magnitude desses problemas desengasta do passado experimentado como história, em uma espécie de inércia contextual, para outros, o que temos a dizer sobre eles é sua história. Conforme adverte Buffa (1990), a única coisa que se pode saber sobre os problemas que nos são atuais é a história dos homens diante deles, "de como eles os enfrentaram, a que ponto chegaram e quais os resultados obtidos" (BUFFA, 1990, p. 13). Penso que as teses de Mendonça (2002), Accácio (1993, 2001), Vidal (2001) e Schaffel (1999) sustentam essa maneira de perceber o patrimônio de ideias e experiências de preparo do magistério. Principalmente em torno da compreensão da história do ISERJ, elaboraram um novo questionário da história docente que privilegia a abordagem pelas práticas.

Uma primeira constatação parece impor-se: esses estudos acerca do projeto de formação que se organizou no ISERJ percebem tal projeto como singular. Não existe a preocupação com uma origem a restituir na sua continuidade com o presente ou com um devir a encontrar. Por conseguinte, náo se trata de lamentar a universidade nem os professores que poderíamos ter tido. $\mathrm{O}$ foco estava nos projetos de reconstrução nacional via educação em disputa nos anos 1920 e 30 e nas manobras para controlar a formação do magistério. Esse conjunto de pesquisas adverte, assim, que não é inócuo perguntar-se a respeito das muitas peças com as quais se arquitetou o projeto de formação do instituto. Em vez do esforço para recolher o que era antes, identificar de onde veio e desvelar uma identidade primeira, debruçou-se sobre as disputas, as manobras e as artimanhas que então ocorreram. $\mathrm{O}$ interesse dessas análises não está na articulação perdida entre uma essência original e os modos de materializá-la, de instituí-la, mas na compreensão dos acontecimentos por meio dos quais se buscou efetivar um modo de preparar professores. Detém-se, dessa forma, naquilo que Foucault (2000) uma vez chamou de síncopes da história: os abalos, as surpresas, as vacilantes vitórias, as derrotas mal digeridas. 
Um segundo conjunto de preocupaçóes colocadas em evidência pelas teses sobre o ISERJ pergunta por quem educa o educador e questiona o modo como a formação para o magistério passou a fazer parte da constituição da identidade docente. Por um lado, suspeita-se da visão excessivamente integrada e homogênea do movimento renovador que deleitou a historiografia por algum tempo. Mais que a coerência de conjunto dos propósitos e das estratégias, póe-se mais ênfase nas diferenciaçóes do que na suposta unidade das açôes. Nessa produção, sobressaem as diferenciaçôes entre Anísio Teixeira, Manoel Bergstrom Lourenço Filho e Fernando de Azevedo conforme indicam as providências de desembaraçar os discursos de reforma ou de circunscrever os conflitos. Como bem percebeu Mendonça (2002), foi principalmente nos diferentes projetos de universidade emergentes no período e na maneira de se conceber a relação entre universidade e formação de professores que as divergências se expressavam. Por outro lado, reconhece-se uma herança que não se pode rejeitar e por meio da qual, nas palavras de Nunes (1990, 1992), o passado é buscado com o intuito de localizar raízes e precedências. Hoje, como atestam os estudos em análise, esse fenômeno da memória é compreendido mais como o resultado de uma multiplicidade de transformaçóes localizadas e circunscritas que a expressão de um legado. As crenças, os valores e as propostas educacionais para a formação do professor no instituto são apreendidas a contrapelo da memória. Em pesquisas como as de Schaffel (1999), a atenção concernente à variedade de vozes e registros que coexistiram no instituto adverte sobre as condiçóes com base nas quais essas crenças e esses valores foram gerados, apropriados e transformados ao longo do tempo. De fato, as análises com um recorte de período mais avançado no tempo auxiliam ver o projeto de esquecimento que se forjou nas disputas em torno da fabricação da memória sobre o instituto.

Um último tema que atravessa a historiografia acerca da formação de professores no ISERJ é o das acepções de ensino. Grosso modo, essa série de pesquisas rompe com o empreendimento de analisar as posições e concepções do grupo que concebeu e estruturou o Instituto de Educação como expressáo de uma visão integrada e homogênea sobre a preparação das elites, da população e dos professores. Tal partido teve consequências no que se refere à forma de caracterizar as ligaçóes que viabilizaram a criação de novos moldes para a formação de professores. Depreende-se dessas pesquisas que, se no Instituto de Educação prevaleceram, de fato, as concepções de Anísio Teixeira acerca da preparação para o exercício do magistério, foi em decorrência de outras posiçóes. Entre Fernando de Azevedo e Anísio Teixeira, entre Anísio Teixeira e Manoel Bergstrom Lourenço Filho, entre Gustavo Capanema e Anísio Teixeira há diferenças de acepção nesse âmbito já bem estudadas e que permitem ter a "percepção do espaço escolar do instituto como um local de conflito e consenso" (VIDAL, 2001, p. 21). Nesse sentido, as singularidades de Anísio Teixeira em relação aos fundamentos do ensino, ao lugar da Escola de Educação na formação de pro- 
fessores secundários e ao caráter intelectual do trabalho docente circunscrevem oposiçōes que frequentemente se deixam de levar em conta na discussão do olhar que então se construiu a respeito das práticas educativas.

Em torno das disputas, das manobras e das artimanhas para controlar a formação de professores, encontram-se, portanto, as preocupações com a singularidade do instituto, com as estratégias de ação dos seus responsáveis e com as acepçôes de preparo docente que expressavam. Essa atenção às forças em disputa pela maneira de realizar a formação docente é contemporânea de um requestionamento muito amplo das instâncias formadoras de professores no contexto das reformas curriculares das universidades na virada dos anos 1980 para os 90 . Ao que parece, em meio às políticas de reforma daquela época e ao debate a respeito do texto da nova LDB, afirmou-se um modelo de interpretaçáo no qual a história dos cursos de preparo para o magistério seria a de uma longa e progressiva marginalização, um domínio da precarização da profissão docente. Para restringirme aos estudos sobre o Instituto de Educação carioca, eles têm em comum, então, além de um conjunto de temas e de preocupaçôes e das condiçóes intelectuais e profissionais, um viés de análise. Todos nasceram em um contexto de questionamentos sobre as transformações da educação pública após a abertura democrática e, especialmente, as mudanças nas políticas de formação de professores, nas quais a desvalorização do magistério foi um dos aspectos principais das discussóes. Quando tratam da história do Instituto de Educação, evocam um projeto apresentado com o Manifesto de 1932 e constituído por seus signatários mais destacados, dois indicativos de uma abrangente proposta liberal de enobrecimento do exercício docente. É das estratégias para sua implementação e dos seus efeitos que eles tratam de fazer o balanço. Diante do estado de coisas em que foram produzidos, os resultados obtidos são de contraste.

Contemporânea da superposição que a Lei no 9.394/96 admitiu entre o curso de Pedagogia e o curso Normal Superior e entre, por um lado, as universidades e faculdades e, por outro, os institutos superiores de educação, além da grande polêmica e radicalizaçáo das posiçóes acerca do local e da natureza do preparo que a nova LDB provocou, a história das manobras para elevar a formação de professores a ensino superior entre 1933 e 1937 foi também uma tomada de partido. Pois não me parece nenhum despropósito o pressuposto de que, para historiadores da educaçáo, tanto a escolha de um objeto tal qual a formação docente quanto o modo segundo o qual aborda esse objeto colocam em questáo uma representaçáo do campo em que atuam e da sua própria posição nesse campo. Penso que o conjunto de pesquisas sobre o ISERJ elaboradas entre 1993 e 2003, ao se deter ao estudo do arranjo organizacional que elevou a formação docente a nível superior, expressou a hostilidade de parte dos professores das universidades e de suas associações à leniência da legislação com um preparo de nível médio ou eminentemente prático para o magistério. Ainda que sem a devida precisão e resultante de uma amostragem bastante reduzida, essa 
interpretação beneficia-se, ao menos, da coincidência de noções baseadas nas quais se deu a discussão.

Nota-se, na ideia de fazer da prática docente o foco formativo do professor, uma primeira instância de confrontação. Diante da suspeita de que a LDB, sua regulamentação e o Plano Nacional de Educação (PNE) provocariam um nivelamento por baixo da qualificação docente ante a ênfase a uma formação estritamente prática, pensar o modo como Anísio Teixeira entendeu a prática de ensino foi também pleitear uma discussão mais complexa sobre a atividade docente. De fato, para Anísio Teixeira, a formação docente deveria ser de tal ordem prática que o centro de gravidade do instituto se constituiria por estabelecimentos anexos de ensino primário organizados para funcionar como laboratórios para a demonstração e a experimentação (MENDONÇA, 2002). Sobretudo, por um lado, tratou-se de enfatizar o quanto ele trabalhou para o instituto tornar eficaz a "normatização dos procedimentos exemplares da práxis do magistério" (VIDAL, 2001, p. 84-85). Por outro, ocorreu acentuar que, na percepçáo de Anísio Teixeira, a prática era constitutiva de uma atitude científica, de experimentação, de ensaio em relação a ideias e teorias, distinguindo-a de uma mera prática nominal do ensino.

Nesse sentido, essa historiografia não cessa de insistir na relação do ensino com a pesquisa no programa de formação de professores do Instituto de Educação. Conforme argumentam Accácio (1993) e Vidal (2001), as Seções de Matérias do Ensino Primário e de Práticas de Ensino da Escola de Professores comportavam-se como um centro de pesquisas. A análise dos processos de aprendizagem da matéria ensinada, a realização de observaçôes diversas e os inquéritos conferiam caráter experimental ao instituto. Pode-se compreender o interesse pela indissociabilidade que havia entre ensino e pesquisa na prática de formação do instituto como uma segunda instância da crítica historiográfica à conjuntura organizada por meio da nova LDB. Outra vez, o entendimento de que a política de ensino superior promovida pela legislação distinguia "universidade de pesquisa" e "universidade de ensino" com a criação dos Institutos Superiores de Educação e Centros Universitários ressignifica as posiçóes liberais no debate educacional dos anos 1930. Mendonça (2002), Nunes (2000) e Brandão e Mendonça (2008) rejeitam as leituras que apontaram o pensamento de Anísio Teixeira e o processo de reforma que conduziu na capital como precursores da visão tecnoburocrática que se tornaria hegemônica na década de 1970 . Central nessa discussão, a indissociabilidade entre teoria da educação, conteúdo de ensino e metodologia na preparação para a docência, mais do que caracterizar um momento histórico ou o tipo ideal de um dispositivo de mudança, sugere haver na análise a convicçáo da necessidade de a formaçáo docente se desenvolver em meio a processos sistemáticos de investigação.

Enfim, crucial para medir a legitimidade social do magistério, a busca do melhor perfil emerge no debate público sobre a educação a cada vez que se 
rediscutem as instituiçóes usadas para autorizar o exercício da docência. Na historiografia sobre o ISERJ, afirma-se o modelo desejado por Anísio Teixeira e Manoel Bergstrom Lourenço Filho, que resultava de uma perspectiva meritocrática e especialmente exigente de ingresso e promoção na carreira. Reunindo critérios rigorosos de admissão à exigência de permanência de oito anos no instituto, procurava-se assegurar um preparo profissional competente a indivíduos já vocacionados para o magistério, a fina flor da população, conforme expressão da época. Na contramão desse tipo de esforço, o disposto no inciso II do artigo 63 da LDB, de 1996, que definiu as atribuiçóes dos institutos superiores de educação, tolera "programas de formaçáo pedagógica para portadores de diplomas de educaçáo superior que queiram se dedicar à educação básica" (BRASIL, 1996, art. 63). Diante do receio da possibilidade de desembarque de uma multidão de profissionais na área da educação apenas com vistas a obter um emprego em tempos de crise econômica, as manobras que se deram no instituto a fim de selecionar os mais aptos para a carreira do magistério ficam acentuadas. Não escapa aos estudos sobre o instituto o modo ostensivo com que então se quis fazer o processo de admissáo e formação expressar a relevância social atribuída ao exercício da docência.

A aproximação sugere, assim, além de um antagonismo fundamental entre o ontem e o hoje, uma perspectiva crítica de compreensão do que se experimentava como desqualificação da profissionalização dos professores. Mas não se trata de uma comparaçáo - nem há paralelos entre o objeto de estudo e a condição em que foi construído, nem qualquer intenção de produzi-los aqui. O passado problematizado por questóes do presente suscita outra ordem de consideraçóes. O reconhecimento de que o passado só adquire existência efetiva com as interrogações do presente e a constatação de que delas também dependem a construçáo de novos conceitos e a ressignificação de antigas noçóes incitam ver na história as necessidades de compreensão do nosso próprio tempo. Nessa perspectiva, a amostragem permite verificar como a relação com o presente beneficia a análise histórica das maneiras de pensar e fazer o preparo para a docência. Conforme os historiadores são reiteradamente advertidos, as questôes correntes orientam a pesquisa e a interpretação. Em uma afirmação lapidar: "Vão esgotar-se em compreender o passado se não se sabe do presente" (BLOCH, 2001, p. 65).

As pesquisas que, entre 1993 e 2003, trataram da formação de professores no ISERJ estão longe de adelgaçar o presente a ponto de deixá-lo transparente, entretanto contribuem para sua inteligibilidade ao discutir a opção política de um grupo de educadores pelo enobrecimento do exercício docente e a maneira como se procurou concretizá-la entre 1932 e 1937. Elas detêm-se sobre a formação docente no ISERJ à época não para lhe restituir o valor do passado, porém para questionar a memória conservada em relação ao projeto, às práticas e aos discursos que deixaram de existir. $\mathrm{O}$ espaço da crítica nesses trabalhos não está na comparação, mas na problemática que suscitam: como respondemos ao desafio de formar para a docência? 


\section{Considerações finais}

Atualmente, assim como no passado, o modo como o preparo para o magistério está organizado institucionalmente e é praticado nos diz algo sobre as respostas que encontramos para a questão da formaçáo docente. Foi isso que visei sublinhar aqui, lembrando que ele é parte das condições nas quais se manifestou e se desenvolveu o interesse da história da educação pela formação do professorado. $\mathrm{O}$ raciocínio que quis sugerir tomou como apoio a historiografia do ISERJ, em razão do resultado de conjunto dessa produção. Tomados em bloco, os estudos que, entre 1993 e 2003, trataram da Escola de Professores, da Escola de Educaçáo ou da UDF propóem uma formulação do problema do preparo para a docência profundamente ancorada na experiência de atuação nessa área dos seus autores. Em alguma medida, dão expressão à afirmação de Mendonça (2002), de que, mesmo abortada, a ambição da proposta de formação que animou o ISERJ "continua viva, entre nós, enquanto idéia, projeto, utopia” (MENDONÇA, 2002, p. 174). E mais: que ela "pertence ao acervo de uma tradição 'desafortunada', sem dúvida, mas que pode e deve constituir o solo para nossa reflexão e ação" (MENDONÇA, 2002, p. 174).

Dessa posição, o conjunto dos estudos em que baseei este ensaio "captura" uma mudança importante na forma como respondemos ao desafio de formar para a docência. A compreensão da história do ISERJ percebe o veio de trabalho que há entre um programa de enobrecimento excludente, seletivo e elitista do preparo do professor no passado e as atuais práticas de desqualificação ampla e geral do exercício docente. Trata-se do intervalo de tempo que separa o processo de construção de um campo autônomo de profissionalização da carreira na educação dos atuais regimes de controle da autonomia profissional do docente. E chegar a ele é apenas o começo da história. As mesmas razóes que fazem Bloch (2001) advertir que a história é filha do seu tempo alertam sobre o gesto inicial do empreendimento da história dos historiadores: o compromisso com o presente.

Pretendo acabar aqui e assim para sublinhar que, por um lado, o acúmulo de estudos sobre a formação docente nos anos 1920 e 30 não parece ser opção casual. Afirma categorias e representaçōes que também servem à construção da realidade que a história descreve e das quais se servem os historiadores para olhar ao seu redor. No caso da amostragem sobre a qual me debrucei, a proposta que materializou o Instituto de Educação da então capital federal, Rio de Janeiro, concorreu com o projeto imposto por Gustavo Capanema (e foi derrotada por ele), mas impôs-se como antípoda do retrocesso, da precarização e da inércia na organização da formação docente. Por esse motivo, creio que uma reflexão do mesmo tipo para São Paulo ou Minas Gerais, por exemplo, em relação aos seus institutos de educação, "não perceberia" mudança diferente. Por outro lado, a historiografia dá uma imagem um tanto coerente dessa antípoda, acentuando seu 
caráter distintivo, sua vocação para a inovação. Não é o caso de questionar agora o modelo de interpretaçáo que acabei de resumir, contudo de instigar outras incursốes nesse mesmo teatro de operaçóes depois da última batalha.

Conforme adverte Thompson (2001, p. 156), "um modelo, por mais flexível que seja o seu emprego, predispóe para que se olhe apenas para certos fenômenos e para examinar a história pelas conformidades, ao passo que é possível que a evidência descartada esconda novos significados". Talvez o atual aviltamento do etos profissional que caracterizou o exercício da docência no serviço público por tanto tempo seja já a evidência da necessidade de voltar à trincheira.

\section{Referências}

ACCÁCIO, L.O. Docentes e catedráticos: os concursos para professor da Escola Normal do Distrito Federal (1928-1930). Tese (Doutorado) - Universidade de São Paulo, São Paulo, 2001.

Instituto de Educação do Rio de Janeiro: a história da formação do professor primário (1927-37). Dissertação (Mestrado) - Universidade Federal do Rio de Janeiro, Rio de Janeiro, 1993.

BLOCH, M. Apologia da história ou o oficio de historiador. Rio de Janeiro: Zahar, 2001.

BRANDÁO, Z.; MENDONÇA, A.W.P.C. (Orgs.). Por que não lemos Anisiso Teixeira? $2^{\mathrm{a}}$ ed. Rio de Janeiro: Formaçăo, 2008.

BRASIL. Lei no 9394, de 20 de dezembro de 1996. Estabelece as Diretrizes e Bases da Educação Nacional. Diário Oficial da Uniāo. Brasília, Ano CXXXIV, no 248, de 23/12/1996, p. 27.833-27.841BUFFA, E. Contribuição da história para o enfrentamento dos problemas educacionais contemporâneos. Em Aberto, Brasília, v. 9, n. 47, p. 13-19, 1990.

CASTRO, L.M.V. Uma escola de professores: formaçáo de docentes na reforma Anísio Teixeira (1931-1935). Dissertação (Mestrado) - Pontifícia Universidade Católica do Rio de Janeiro, Rio de Janeiro, 1986.

CARVALHO, M. Apresentação. In: VIDAL, D. O exercício disciplinado do olhar: livros, leituras e práticas de formação docente no Instituto de Educação do Distrito Federal (1932-1937) Bragança Paulista: Editora da Universidade São Francisco, 2001. p. 11-14.

FOUCAULT, M. Nietzsche, a genealogia, a história. In: Arqueologia das ciências e história dos sistemas de pensamento. Rio de Janeiro: Forense Universitária, 2000. p. 260-281.

LOPES, S.C. Oficina de mestres. História, memória e silêncio sobre a Escola de Professores do Instituto de Educação do Rio de Janeiro (1932-1939). Rio de Janeiro: DP\&A; FAPERJ, 2006.

MENDONÇA, A.W.P.C. Anísio Teixeira e a Universidade de Educação. Rio de Janeiro: Eduerj, 2002.

Universidade e formação de professores: uma perspectiva integradora - a Universidade de Educação de Anísio Teixeira. Tese (Doutorado) - Pontifícia Universidade Católica do Rio de Janeiro, Rio de Janeiro, 1993. 
NUNES, C. História da educação: espaço do desejo. Em Aberto, Brasília, v. 9, n. 47, p. 37-45, 1990.

. História da educação brasileira: novas abordagens de velhos objetos. Teoria e Educação, n. 6, p. 151-181, 1992.

. Anisio Teixeira: a poesia da ação. Bragança Paulista: Edusf, 2000.

SCHAFFEL, S.L. Instituto de Educação do Rio de Janeiro: a construção da identidade do professor (1930-1960). Tese (Doutorado)-Pontifícia Universidade Católica do Rio de Janeiro, Rio de Janeiro, 1999.

THOMPSON, E.P. As peculiaridades dos ingleses e outros artigos. Campinas: Editora da Unicamp, 2001.

VIDAL, D.G. O exercício disciplinado do olhar: livros, leituras e práticas de formação docente no Instituto de Educação do Distrito Federal (1932-1937). Tese (Doutorado) Universidade de São Paulo, São Paulo, 1995.

O exercício disciplinado do olhar: livros, leituras e práticas de formação docente no Instituto de Educação do Distrito Federal (1932-1937). Bragança Paulista: Editora da Universidade São Francisco, 2001.

Recebido em 30 de agosto de 2014.

Aprovado em 26 de julho de 2016. 